\title{
Quantitative Dynamic Measures of Physical Exposure Predict Low Back Functional Impairment
}

\author{
William S. Marras, PhD, Steven A. Lavender, PhD, Sue A. Ferguson, PhD, \\ Riley E. Splittstoesser, and Gang Yang, MD
}

Study Design. Prospective field study of work exposure and changes in back function.

Objective. Quantify dynamic physical exposures in the workplace and their association with decreases in kinematic back function (indicative of low back pain [LBP]).

Summary of Background Data. Previous epidemiologic studies of work have measured gross categories of exposure and found moderate relationships with LBP. More precise quantitative measures of exposure and spine function were hypothesized to increase the chances of identifying any significant associations.

Methods. Three hundred and ninety real-time physical exposure measures were collected from distribution center workers performing repetitive manual materials handling tasks. Low back health effect measures were quantitatively measured prospectively for workers performing each of the jobs using a kinematic measure of function.

Results. Significant decreases in spine function were observed in workers associated with $40 \%$ of the jobs sampled. Numerous significant univariate odds ratios were identified that indicated an association between physical exposure and decreased function. A multivariate model including right lateral trunk velocity, timing of the maximum dynamic asymmetric load moment exposure, and the magnitude of the dynamic sagittal bending moment predicted reduced spine function well. The model resulted in excellent sensitivity (85\%) and specificity (87.5\%) as well as excellent positive predictive value (89.5\%) and negative predictive value ( $82.4 \%$ ).

Conclusion. This study suggests that with proper quantification of job exposure and spine function, it is possible to identify which dynamic physical exposures are associated with reduced spine function and increases in LBP.

Key words: low back pain, low back disorder, biomechanics, spine motion, kinematics, kinetics, ergonomics, workplace, occupation, functional impairment, epidemiology, load moment, spine mechanics, lumbar spine. Spine 2010;35:914-923

It has been well recognized that low back pain (LBP) risk is associated with a combination of personal factors (e.g., genetics), psychological or psychosocial factors,

From the Biodynamics Laboratory, The Ohio State University, Neil Avenue, Columbus, $\mathrm{OH}$

Acknowledgment date: July 29, 2009. First revision date: September 23, 2009. Acceptance date: October 28, 2009.

The manuscript submitted does not contain information about medical device(s)/drug(s).

Federal funds were received in support of this work. No benefits in any form have been or will be received from a commercial party related directly or indirectly to the subject of this manuscript.

Supported partially by the National Institute for Occupational Safety and Health (NIOSH) grant No. U01 OH07313.

This study was approved by the IRB of the Ohio State University.

Address correspondence and reprint requests to William S. Marras, Biodynamics Laboratory, The Ohio State University, 1971 Neil Avenue, Columbus, OH 43210; E-mail: marras.1@osu.edu and physical exposures. ${ }^{1}$ Currently, it is difficult, if not impossible, to modify most individual or psychological factors. However, it is possible to mediate exposure to many of the physical factors encountered in the workplace. In an attempt to control the high cost of LBP, it has been demonstrated that it is possible to influence LBP rates in the workplace by minimizing physical risk factor exposure. $^{2}$

The relationship between occupational LBP and physical risk factors has been previously investigated primarily in field surveillance studies. ${ }^{3-9}$ However, the majority of these studies have categorized physical risk factors in gross terms, such as lifting and forceful movements, heavy physical work, awkward postures, and static postures. When risk has been categorized in such a gross manner, significant but low odds ratios (ORs) between risk factors and LBP occurrence have been reported. On the other hand, when the risk factors are described more quantitatively, the ability to identify relationships between LBP and risk increase substantially. ${ }^{1}$

Furthermore, epidemiologic studies have typically considered physical risk factor exposure in a binary fashion (i.e., the risk factor is either present or absent). With such an approach, the ability to identify risk significance depends greatly on the investigator's ability to identify correct exposure "thresholds" so that when workers are exposed beyond the point they are in the exposed category and when their exposure is below the threshold they are considered unexposed. When these thresholds are defined arbitrarily (e.g., lifting $10 \mathrm{~kg}$ or more), the ability to identify how the risk factor relates to tissue loading is difficult to assess and the ability to identify a doseresponse relationship may be lost. Furthermore, some risk factors are defined so vaguely (e.g., heavy work), and it is virtually impossible to describe what qualifies as such an exposure, given different interpretations of the risk factor and the potential problems with self-reported exposure.

In reality, workers are typically exposed to varying degrees of a risk factor throughout a workday. The ability to more quantitatively assess risk exposure throughout the workday would enable one to better assess the relationship between physical exposure and LBP risk. Given today's technologic advances, it is now possible to describe exposure to physical risk factors with a degree of accuracy that has not been previously available. Armed with proper physical exposure measurements, it is now possible to assess the precise role of physical exposure in LBP risk through an assessment of "how much 
exposure is too much exposure" to an individual risk factor or combination of risk factors.

The few earlier studies that have attempted to precisely quantify physical exposure at the workplace have suggested that increased risk of LBP is associated with load moment exposure, increases in dynamic trunk motion, frequency of exposure, and the maximum trunk angle required by the task. ${ }^{4,5,10}$ However, the strongest association between physical risk factors and LBP risk was associated with peak load moment exposure (OR, 5.17), and this variable was quantified in a relatively crude manner. ${ }^{5}$ In these studies, load moment was evaluated by estimating the distance of the object lifted from the spine (using a tape measure) and multiplying the weight of the object (using a bathroom scale). Such a crude measure ignores many of the factors that contribute to biomechanical loading of the spine, such as dynamic characteristics of the object handled, directions of load moment relative to the spine (e.g., asymmetry), torso movements, load height when lifted, etc. Because the load moment variable holds such promise, we hypothesized that a much better assessment of risk can be derived if load moment and the relevant biomechanical variables associated with exposure were better quantified.

In this study, a state-of-the art moment monitor capable of quantifying numerous physical exposure variables over the course of a workday ${ }^{11}$ was used to assess exposure in distribution center environments. The goal of this study was to assess the relationship between exposures to physical factors in such environments and changes in low back function over time. Specifically, our hypotheses were (1) jobs with specific occupational exposures to physical risk factors will prospectively lead to decrements in low back function over time, and (2) a sensitive and specific multivariate model could be developed that characterizes physical exposures linked with jobs associated with low back function impairment over time.

\section{- Materials and Methods}

\section{Experimental Design}

This study consisted of a prospective field study that quantitatively monitored health effects of workers performing materials handling work in distribution centers and quantitatively documenting the physical exposure in the workplace. In these evaluations, the jobs (as opposed to the workers) were the unit of analysis of interest.

Figure 1 graphically represents this prospective study design. At the baseline, all workers involved in manual materials handling tasks (i.e., order picking, truck loading and unloading, and stock replenishment) in the distribution centers were invited to participate in the study, signed institutional review board consent forms, and then were evaluated for low back health status. The health effect evaluations consisted of (1) background history of their employment (e.g., years on the job, previous jobs, etc.), (2) questionnaire asking about health history, psychosocial impressions, perceptions of work, etc., and (3) a kinematic back functional assessment to measure impairment status.

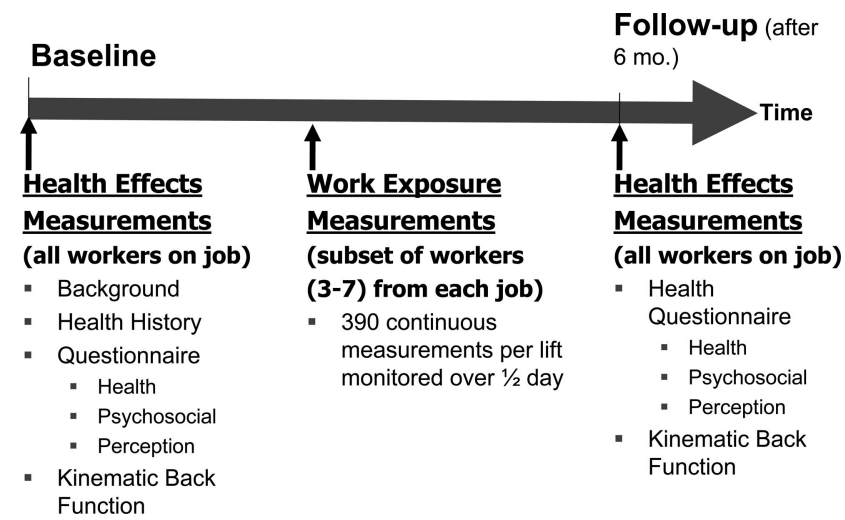

Figure 1. Prospective study design flow.

After the baseline health effects data were collected but before the health effects follow-up, work physical exposure measures were collected from a subset of workers performing each job in the distribution center. The number of workers recruited for work exposure measurement depended on the number of workers employed in the particular job; however, in general between 3 and 7 workers were typically monitored on each job. Previous studies ${ }^{10}$ have demonstrated that a minimum of 3 workers are necessary to adequately document the physical characteristics of the workplace.

At least 6 months after the baseline, low back health effects measures were collected and follow-up health effects measures were collected from all workers that remained (did not change jobs) in jobs of interest.

The analyses compared characteristics of the jobs in which at least $30 \%$ of workers (assigned to the job) demonstrated a significant reduction in spine function (high LBP risk) with the jobs in which workers exhibited no such reduction in spine function (low-risk jobs).

Data Collection Sites. The data collection sites were comprised of distribution center organizations in which employees perform repetitive material handling tasks continuously throughout the day. Data were collected from grocery, automotive parts, clothing, and general merchandise distribution centers. Given the similarity of "jobs" within distribution centers, jobs were differentiated on the basis of the department (or section) of work exposure (where workers did not "float" from one department to another). For example, a grocery distribution operation may have 3 to 4 jobs, depending on how orders are distributed. Usually, employees "select" in dry groceries, produce, frozen foods, or boxed meats. Hence, a grocery facility with these 4 areas would potentially contribute 4 jobs to the database.

Overall, a total of 19 different distribution centers were included in this study. Four categories (types) of products were handled by the employees within these distribution centers. A total of 48 jobs were identified within these facilities. Table 1 summarizes the types of products handled and the number of jobs sampled from each type of distribution centers.

Health Effects Sampling. Figure 2 describes the number of workers who were included in the health effects sampling at the baseline and those who survived in their job until follow-up. Initially, 888 workers were enrolled in this study. At the followup, 366 of the workers had left the job and were unavailable for follow-up. Of the 522 remaining, 72 were eliminated because 
Table 1. The Number of Jobs Sampled by Distributed Product Type

\begin{tabular}{lcc}
\hline Type of DC & No. of Facilities & No. of Jobs \\
\hline Grocery & 6 & 15 \\
Auto parts & 4 & 8 \\
Clothing & 5 & 12 \\
General merchandise & 4 & 13 \\
\hline
\end{tabular}

they no longer were assigned to the same job. Therefore, 450 workers were available for analysis at follow-up. This represents a follow-up rate of slightly $>50 \%$. Of these workers, 332 met the classification criteria based on their kinematic signature (low back functional impairment evaluation). Employees were given a hat or $\mathrm{t}$-shirt in exchange for participating in each of the health effects data collections (baseline and follow-up).

Health History, Work History, and Psychosocial Assessment. Each worker was asked to fill out a survey that assessed their current LBP experience. The survey was comprised of items extracted from the National Institute for Occupational Safety and Health health effects assessment instrument. ${ }^{12}$ This survey was designed to document prior LBP events and work history. In addition, questions were included to document psychosocial impressions of the work. These characteristics are summarized in Table 2.

Low Back Functional Impairment Evaluation. To quantitatively document the functional status of the low back, workers in each job were asked to participate in kinematic back functional assessments. These workers interacted with a computer while wearing a clinical lumbar motion monitor to document kinematic capacity in 3-dimensional space using the assessment protocol described previously in the literature. ${ }^{13}$ This assessment provided objective data describing the back's kinematic function and represents an independent assessment from the injury reporting system at the distribution centers. The model underlying this analysis has excellent sensitivity $(90 \%)$ and specificity $(92 \%)$ in its ability to correctly differentiate those with and without back pain. ${ }^{14,15}$ By comparing each employee's kinematic profile with that of a normative database, the model is able to quantify how that worker's kinematic function

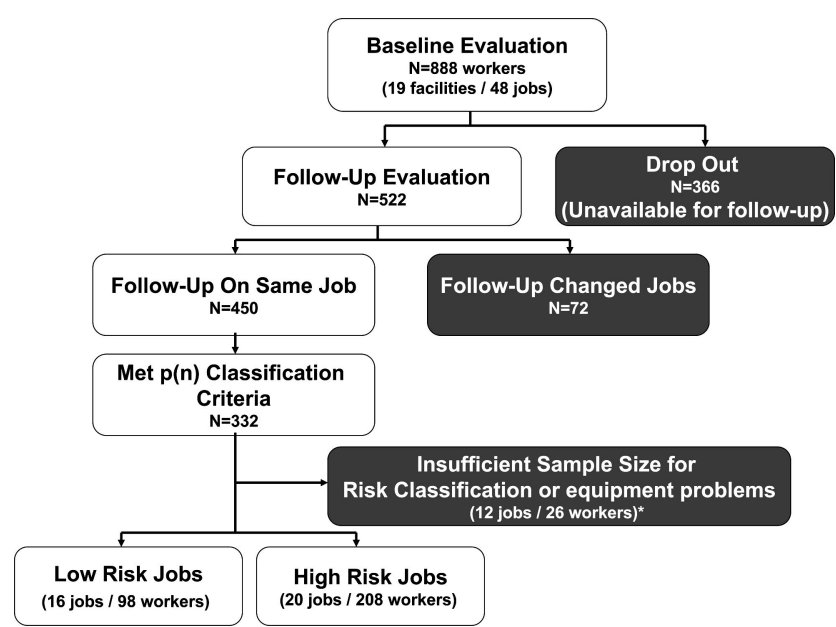

Figure 2. Health effects sample size at baseline and at follow-up ${ }^{*}$ data from 1 job was eliminated because of equipment problems in a freezer environment; 7 workers were eliminated). (percentage of the combination of outcome measures) compares with that which would be expected of a person of that age and gender (expected normal kinematic function). The worker's kinematic back function is scaled relative to the expected normal kinematic function (for an individual) and is defined as the probability of normal or $\mathrm{p}(\mathrm{n})$. Thus, a $\mathrm{p}(\mathrm{n})$ of 0.5 indicates that the subject is performing at a level of function that is $50 \%$ of what would expected for that subject's age and gender. This analysis is also able to identify whether a subject is magnifying their impairment. ${ }^{16}$

Recently, Ferguson $e t \mathrm{al}^{17}$ have reported that a decrease in $\mathrm{p}(\mathrm{n})$ of $0.14(14 \%)$ represents a meaningful (statistically significant and functionally significant) increase in low back impairment. This value was used as a minimum benchmark for determining kinematic functional impairment changes in individual workers between the baseline measure of impairment and the follow-up measurement of impairment.

Physical Exposure Sampling. Physical exposure sampling was performed on 193 of the workers employed in the jobs of interest. Quantitative physical exposure data were obtained using custom instrumentation developed specifically for this project and described previously in the literature. ${ }^{11}$ Figure 3 shows a worker wearing this instrumentation while performing their job. The instrumentation is contained within an instrumented backpack that is worn by the worker. Handles, used by the worker to lift the load, measure static and dynamic load characteristics and document the direction of effort. The handles also emit ultrasound that is received by sensors positioned around the backpack frame. The ultrasound receivers triangulate the handle locations, which enable the backpack to document the travel path of the load. The backpack also contains accelerometers that document trunk motions. Software translated the exposures relative to L5/S1. Detailed descriptions of the instrumentation and performance can be found elsewhere ${ }^{11}$ Force measurement accuracy is within $0.5 \mathrm{~kg}(1.1 \mathrm{lb}$.), and position accuracy (average absolute error) is within $3.0 \mathrm{~cm}$ (1.2 in.). This represents accuracy that is 4 times more accurate than previous measurements and also is able to document dynamic load moment exposure for the first time at the worksite. This system enables the continuous monitoring and recording of 3-dimensional hand locations relative to both L5/S1 and the ground, the instantaneous load weight (static and dynamic), the orientation of the torso, and the timing of lifting events, and a variety of derived measures (e.g., moment arms, static and dynamic load moments, etc.). Data were continuously collected using the built-in microprocessor and stored on memory flash cards for later analysis. The data processing programs used the hand load exposure information to identify lift initiation and termination points, and thereby, identified the intervals of time during which lifting is occurring and the interlift (rest) periods. The system collects 390 variables for each lift performed by the worker.

Workers involved in physical exposure sampling were randomly chosen from the pool of workers performing the job. The workers signed informed consent documents and were compensated for their participation with gift cards from area merchants. Each employee was monitored for up to 4 hours (median $=2.83$ hours) and asked to perform their job and match their normal productivity rates.

Subjects. Table 3 describes the anthropometric characteristics of the workers tested for health effects at baseline and follow-up as well as for the workers selected for exposure test- 


\begin{tabular}{|c|c|c|c|}
\hline Variable & Baseline & $\begin{array}{c}\text { All Follow-Up } \\
\text { Regardless of } p(n) \\
\text { Change }(\mathrm{N}=450)\end{array}$ & $\begin{array}{l}\text { Follow-Up Workers Found to } \\
\text { Have Meaningful Change in } \\
\qquad(n)^{17}(N=332)\end{array}$ \\
\hline \multicolumn{4}{|l|}{ Individual } \\
\hline Percentage of Hispanic or Latino workers & 5 & 5 & 5 \\
\hline \multicolumn{4}{|l|}{ Race, \% } \\
\hline White & 75 & 77 & 78 \\
\hline Black & 20 & 18 & 16 \\
\hline Other & 2 & 2 & 3 \\
\hline Missing data & 3 & 3 & 3 \\
\hline Percentage of smokers & 53 & 51 & 52 \\
\hline \multicolumn{4}{|l|}{ How long have you worked at this company?, \% } \\
\hline$<3$ mon & 8 & - & - \\
\hline $3 \mathrm{mon}$ to $<1 \mathrm{yr}$ & 22 & 8 & 8 \\
\hline $1 \mathrm{yr}$ to $<3 \mathrm{yr}$ & 20 & 25 & 24 \\
\hline $3 \mathrm{yr}$ to $<5 \mathrm{yr}$ & 17 & 19 & 19 \\
\hline $5 \mathrm{yr}$ to $<10 \mathrm{yr}$ & 22 & 32 & 31 \\
\hline 10 yr or more & 10 & 15 & 18 \\
\hline \multicolumn{4}{|c|}{ How long have you worked in your current job?, \% } \\
\hline$<3$ mon & 11 & - & - \\
\hline 3 mon to $<1 \mathrm{yr}$ & 25 & 13 & 14 \\
\hline $1 \mathrm{yr}$ to $<3 \mathrm{yr}$ & 24 & 29 & 28 \\
\hline $3 \mathrm{yr}$ to $<5 \mathrm{yr}$ & 18 & 20 & 20 \\
\hline $5 \mathrm{yr}$ to $<10 \mathrm{yr}$ & 17 & 27 & 27 \\
\hline 10 yr or more & 5 & 10 & 10 \\
\hline \multicolumn{4}{|c|}{ How long have you been doing this kind of work?, \% } \\
\hline$<3$ mon & 5 & - & - \\
\hline $3 \mathrm{mon}$ to $<1 \mathrm{yr}$ & 14 & 7 & 8 \\
\hline $1 \mathrm{yr}$ to $<3 \mathrm{yr}$ & 15 & 20 & 21 \\
\hline $3 \mathrm{yr}$ to $<5 \mathrm{yr}$ & 18 & 18 & 17 \\
\hline $5 \mathrm{yr}$ to $<10 \mathrm{yr}$ & 26 & 28 & 26 \\
\hline 10 yr or more & 21 & 27 & 28 \\
\hline \multicolumn{4}{|l|}{ Hours worked, \% } \\
\hline $20-39 \mathrm{~h}$ & 13 & 8 & 8 \\
\hline $40 \mathrm{~h}$ & 56 & 58 & 58 \\
\hline $41-60 \mathrm{~h}$ & 30 & 31 & 32 \\
\hline$>61 \mathrm{~h}$ & 1 & 2 & 2 \\
\hline \multicolumn{4}{|l|}{ Psychosocial } \\
\hline Job control, mean (SD) & $2.83(1.04)$ & $2.86(0.97)$ & $2.80(0.97)$ \\
\hline Social support from boss, mean (SD) & $1.65(0.73)$ & $1.74(0.74)$ & $1.74(0.75)$ \\
\hline Social support from co-worker, mean (SD) & $1.77(0.67)$ & $1.73(0.67)$ & $1.74(0.61)$ \\
\hline Job satisfaction, mean (SD) & $2.09(0.76)$ & $2.17(0.69)$ & $2.20(0.66)$ \\
\hline Perception of physical demand, mean (SD) & $5.99(2.46)$ & $5.95(2.43)$ & $5.94(2.43)$ \\
\hline
\end{tabular}

ing. This table indicates that most workers were relatively young and there were no statistically significant differences in anthropometric measures between the physical exposure group and the health effects group. However, there were differences in age and height between subjects that dropped out of the study and those that remained for follow-up with dropouts being younger and taller.

Physical Exposure Database Development. The total physical exposure database consisted of 78,360 exertions. For the purposes of this analysis, lifts and lowers were of interest. Pushing and pulling exertions were considered in a separate analysis. Therefore, 59,796 exertions were considered in this analysis. Of these exertions, 42,005 were classified as lifts and 16,791 exertions were classified as lowers. Custom software was developed to analyze each of the exertions.

For this analysis, 227 variables were included in this physical exposure database. Descriptive characteristics of the variables are reported elsewhere. ${ }^{18}$ This analysis focuses on the association between physical exposure characteristics and the decreases in low back kinematic function.
Data Analysis. This analysis attempted to assess the relationships between physical exposure characteristics and an elevated risk of a decrement in spine kinematic function (impairment) in both a univariate and multivariate fashion. To accomplish this goal, it was necessary to identify those jobs that placed the worker at greater risk of spine functional impairment.

Job Risk Definitions. Jobs at high risk for significant increase in kinematic spine functional impairment were operationally defined as a job in which at least $30 \%$ of the workers experienced a meaningful ${ }^{17} \mathrm{p}(\mathrm{n})$ decrease of at least 0.14 between the baseline and follow-up health effect measurement times. Individuals with a nonmeaningful decrease in kinematic spine functional impairment were eliminated from further analyses. This left 332 workers for further consideration. Of the 48 distribution center jobs studied, if fewer than 3 workers remained on the job at follow-up, the job was not included in the analysis. Eleven jobs were eliminated on the basis of this rationale (19 workers). In addition, 1 job consisted of food distribution in a freezer environment that had to be eliminated 


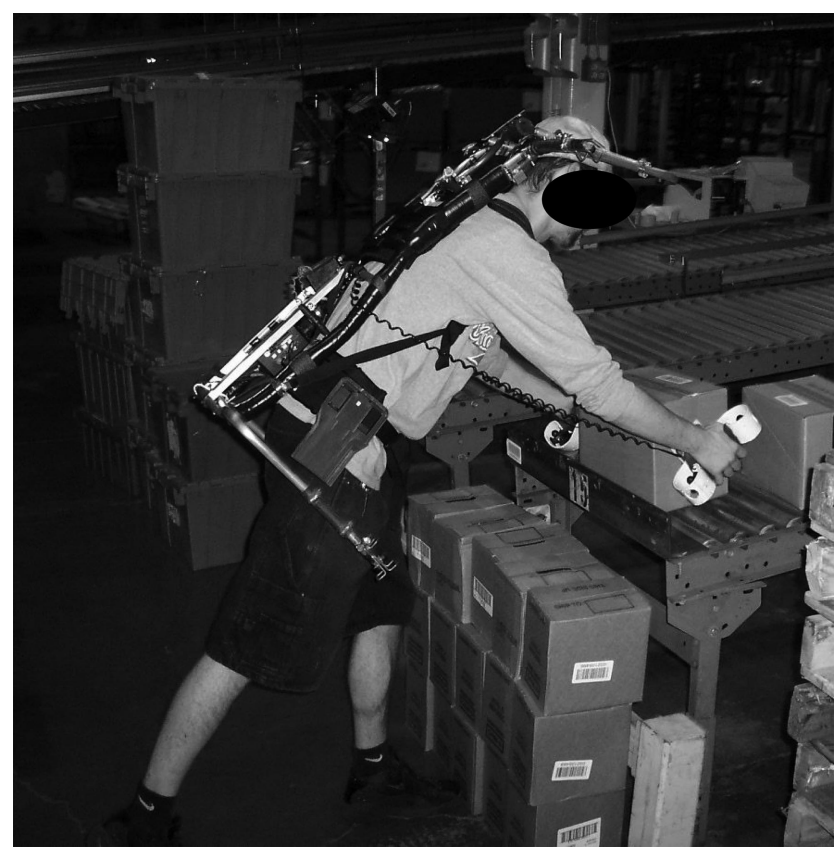

Figure 3. Subject wearing instrumentation used to monitor physical exposure effects at the workplace.

when the temperature affected the exposure instrumentation (7 workers). Of the remaining jobs, 20 (representing 208 workers) were classified as high-risk jobs, according to this definition. Jobs at low risk for spine kinematic functional impairment were operationally defined as those jobs in which $<30 \%$ of workers demonstrated a meaningful decrease in spine kinematic function between the 2 health effects measurement points. Sixteen jobs (98 workers) were classified as low risk according to this definition. These jobs were eliminated from the analysis. Hence, for the purposes of this analysis, the 20 high-risk jobs were compared with the 16 low-risk jobs (Figure 2).

Univariate Analyses. ORs were computed to evaluate the relationship between the value of the physical exposure measure and the probability that the measure was associated with the high-risk jobs versus the low-risk jobs. OR confidence intervals were determined and significance was determined if the confidence interval did not include the 1.0 (even odds) threshold.

Multivariate Analyses. The Classification and Regression Tree $\left(\right.$ CART) ${ }^{19,20}$ analysis software was used to select and assess the conditional relationship between the physical exposure variables relative to job risk. The CART analysis was offered physical exposure variables from each category of variable (i.e., load, timing, kinematics, psychosocial, etc.), and the analysis iteratively chose the variables and identified the value of the variable (cut point) that best distinguished between the highrisk jobs and low-risk jobs. Once these variables were identified, multivariate logistic regression models were developed to assess the sensitivity, specificity, and the positive and negative predictive values of the models.

\section{- Results}

\section{Health Effects}

The changes in spine function from baseline to follow-up collectively among all jobs indicated a $0.03 \mathrm{p}(\mathrm{n})$ decrement. This represented a nonsignificant statistical change. However, among specific jobs, significant increases in back impairment measures ${ }^{17}$ were confirmed in 20 of the 48 jobs studied. These jobs were considered high risk.

\section{Physical Exposure}

A subset of the 227 exposure variables associate with each lift were considered in this analysis. Descriptive statistics associated with the key position, load, and timing categories of these variables over all exposures are published elsewhere. ${ }^{18}$ Descriptive statistics describing the exposures in the high- and low-risk jobs are reported in Table 4.

\section{Univariate Odds Ratios}

Univariate ORs assessing the linearity of the association between each of the key exposure variables and their association with high or low risk of LBP impairment (as a function of the job) is shown in Table 4. This table evaluates the continuous nature of the variable where the $\mathrm{OR}$ is calculated as a function of each unit change in variable. Significant ORs among these exposure variables indicate that there is a linear change in risk throughout the entire range of variable observations. Thus, significant ORs indicate that it would be prudent to minimize worker exposure to as low a value as possible. The variables with the greatest linear association with risk consisted of (1) the duration of the task, (2) duration of the carry, (3) maximum lateral trunk angle, (4) ending asymmetry, and (5) dynamic twisting slide moment.

Table 3. Anthropometry Characteristics of Subjects Participating in Different Components of the Study

\begin{tabular}{|c|c|c|c|c|c|c|}
\hline & \multicolumn{4}{|c|}{ Health Effects* } & \multicolumn{2}{|c|}{ Physical Exposure* } \\
\hline & $\begin{array}{l}\text { Baseline } \\
(\mathrm{N}=888)\end{array}$ & $\begin{array}{l}\text { Drop Outt } \\
\text { (N = 438) }\end{array}$ & $\begin{array}{l}\text { Follow-Up } \\
(\mathrm{N}=450)\end{array}$ & $\begin{array}{l}P \text { (Drop Out vs. } \\
\text { Follow-Up) }\end{array}$ & $\begin{array}{l}\text { Moment Monitor } \\
\quad(\mathrm{N}=193)\end{array}$ & $\begin{array}{l}P \text { (Follow-Up vs. } \\
\text { Exposure) }\end{array}$ \\
\hline Age (yrs) & $33.9(10.7)$ & $31.0(9.6)$ & $36.8(10.9)$ & 0.0001 & $36.3(10.9)$ & 0.5938 \\
\hline Height $(\mathrm{cm})$ & $176.6(9.3)$ & $177.6(7.6)$ & $175.6(9.9)$ & 0.0009 & $175.8(8.9)$ & 0.0914 \\
\hline Weight $(\mathrm{kg})$ & 85.1 (19.5) & 84.7 (19.6) & 85.6 (19.4) & 0.5861 & 82.8 (17.9) & 0.8422 \\
\hline$\%$ Male & 85 & 88 & 82 & 0.0089 & 83 & 0.7990 \\
\hline
\end{tabular}

*Health effects group is self-reported, and physical exposure was measured.

tDrop out include job changes, no opportunity for follow-ups. 
Measures of Physical Exposure Predict Impairment • Marras et al 919

Table 4. Descriptive Statistics and Univariate Odds Ratios to Assess the Linearity of Risk Associated With Various (Continuous) Variables

\begin{tabular}{|c|c|c|c|c|c|c|}
\hline Variable (Units) & $\begin{array}{l}\text { Low Risk, } \\
\text { Mean (SD) }\end{array}$ & $\begin{array}{l}\text { High Risk, } \\
\text { Mean (SD) }\end{array}$ & Beta & $\begin{array}{l}\text { Standard } \\
\text { Error }\end{array}$ & $\begin{array}{l}\text { Odds } \\
\text { Ratio }\end{array}$ & $\begin{array}{l}95 \% \text { Confidence } \\
\text { Interval }\end{array}$ \\
\hline \multicolumn{7}{|l|}{ Load variables } \\
\hline Load weight (N) & $59.82(13.69)$ & $69.11(13.86)$ & 0.067 & 0.011 & $1.07^{*}$ & $1.05-1.09$ \\
\hline Maximum dynamic lift force (N) & $86.64(20.43)$ & $104.23(29.58)$ & 0.030 & 0.005 & $1.03^{*}$ & $1.02-1.04$ \\
\hline Abs. maximum dynamic slide force (N) & $37.31(12.78)$ & $43.69(12.78)$ & 0.081 & 0.012 & $1.08^{*}$ & $1.06-1.11$ \\
\hline Abs. maximum dynamic lift/slide force (N) & $93.02(22.19)$ & $112.67(30.68)$ & 0.035 & 0.005 & $1.04^{*}$ & $1.02-1.05$ \\
\hline Abs. maximum static transverse plane load moment $(\mathrm{Nm})$ & $30.04(7.75)$ & $36.39(8.40)$ & 0.124 & 0.018 & $1.13^{*}$ & $1.09-1.17$ \\
\hline Abs. average static transverse plane load moment (Nm) & $20.46(5.36)$ & $23.96(5.31)$ & 0.166 & 0.028 & $1.18^{*}$ & $1.12-1.25$ \\
\hline Abs. maximum static forward-bend load moment (Nm) & $29.36(7.64)$ & $35.50(8.18)$ & 0.126 & 0.019 & $1.13^{*}$ & $1.09-1.18$ \\
\hline Abs. maximum static side-bend load moment (Nm) & $9.67(2.34)$ & $12.52(3.24)$ & 0.460 & 0.060 & $1.58^{*}$ & $1.41-1.78$ \\
\hline Maximum static right side-bend load moment (Nm) & $7.87(2.13)$ & $9.87(2.41)$ & 0.520 & 0.071 & $1.68^{*}$ & $1.46-1.93$ \\
\hline Maximum static left side-bend load moment (Nm) & $6.91(1.75)$ & $9.51(3.06)$ & 0.543 & 0.074 & $1.72^{*}$ & $1.48-1.99$ \\
\hline Abs. maximum dynamic forward-bend load moment (Nm) & $35.13(9.66)$ & $44.27(13.03)$ & 0.075 & 0.012 & $1.08^{*}$ & $1.05-1.10$ \\
\hline Abs. maximum dynamic side-bend load moment (Nm) & $10.26(2.56)$ & $13.25(4.10)$ & 0.300 & 0.045 & $1.35^{*}$ & $1.24-1.48$ \\
\hline Maximum dynamic right side-bend load moment (Nm) & $8.09(2.24)$ & $9.90(2.79)$ & 0.338 & 0.058 & $1.40^{*}$ & $1.25-1.57$ \\
\hline Maximum dynamic left side-bend load moment (Nm) & $6.83(1.72)$ & $9.66(3.67)$ & 0.436 & 0.064 & $1.55^{*}$ & $1.36-1.76$ \\
\hline $\begin{array}{l}\text { Abs. maximum dynamic transverse plane load moment } \\
(\mathrm{Nm})\end{array}$ & $36.11(9.89)$ & $45.54(13.41)$ & 0.073 & 0.012 & $1.08^{*}$ & $1.05-1.10$ \\
\hline $\begin{array}{l}\text { Abs. average dynamic transverse plane load moment } \\
(\mathrm{Nm})\end{array}$ & $19.12(5.24)$ & $21.11(5.19)$ & 0.090 & 0.025 & $1.09^{*}$ & $1.04-1.15$ \\
\hline $\begin{array}{l}\text { Abs. maximum dynamic forward-bending resultant } \\
\text { (sagittal) moment (Nm) }\end{array}$ & $35.58(8.67)$ & $45.59(13.65)$ & 0.090 & 0.013 & $1.10^{*}$ & $1.07-1.12$ \\
\hline Abs. maximum dynamic resultant moment (Nm) & $36.65(8.90)$ & $47.00(14.06)$ & 0.088 & 0.012 & $1.09^{*}$ & $1.07-1.12$ \\
\hline Abs. average dynamic resultant moment $(\mathrm{Nm})$ & $20.58(4.68)$ & $23.36(6.17)$ & 0.138 & 0.026 & $1.15^{*}$ & $1.09-1.21$ \\
\hline Abs. maximum dynamic twisting slide moment (Nm) & $4.25(1.32)$ & $5.51(2.07)$ & 0.706 & 0.097 & $2.03^{*}$ & $1.68-2.45$ \\
\hline Abs. maximum dynamic forward-bend slide moment (Nm) & $9.39(3.12)$ & $11.42(3.84)$ & 0.291 & 0.042 & $1.34^{*}$ & $1.23-1.45$ \\
\hline Abs. maximum dynamic lateral plane slide moment (Nm) & $10.13(3.26)$ & $12.33(4.13)$ & 0.276 & 0.039 & $1.32^{*}$ & $1.22-1.42$ \\
\hline \multicolumn{7}{|l|}{ Position variables } \\
\hline Maximum transverse plane moment arm (cm) & $49.31(4.31)$ & $51.86(3.63)$ & 0.189 & 0.037 & $1.21^{*}$ & $1.12-1.30$ \\
\hline Start transverse plane moment arm $(\mathrm{cm})$ & $42.63(4.19)$ & $43.46(3.46)$ & 0.093 & 0.038 & $1.10^{*}$ & $1.02-1.18$ \\
\hline End transverse plane moment arm $(\mathrm{cm})$ & 39.62 (4.18) & $42.13(3.85)$ & 0.151 & 0.039 & $1.16^{*}$ & $1.08-1.25$ \\
\hline Maximum resultant moment arm $(\mathrm{cm})$ & $57.65(5.13)$ & $60.72(4.20)$ & 0.148 & 0.029 & $1.16^{*}$ & $1.09-1.23$ \\
\hline Start height $(\mathrm{m})$ & $0.91(0.10)$ & $0.92(0.09)$ & 0.093 & 0.038 & $1.10^{*}$ & $1.02-1.18$ \\
\hline End height (m) & $1.08(0.10)$ & $1.02(0.12)$ & 0.151 & 0.039 & $1.16^{*}$ & $1.08-1.25$ \\
\hline Start asymmetry (degrees) & $88.10(2.44)$ & $89.82(2.20)$ & 0.492 & 0.069 & $1.64^{*}$ & $1.43-1.88$ \\
\hline End asymmetry (degrees) & $87.76(2.03)$ & $89.80(2.09)$ & 0.786 & 0.095 & $2.20^{*}$ & $1.82-2.64$ \\
\hline Abs. maximum forward moment arm $(\mathrm{cm})$ & $48.13(4.23)$ & $50.59(3.61)$ & 0.642 & 0.087 & $1.90^{*}$ & $1.60-2.26$ \\
\hline Abs. maximum side moment arm $(\mathrm{cm})$ & $16.17(1.50)$ & $17.76(1.94)$ & 0.184 & 0.037 & $1.20^{*}$ & $1.12-1.29$ \\
\hline Abs. maximum up moment arm $(\mathrm{cm})$ & $34.59(4.66)$ & $36.68(4.41)$ & 0.130 & 0.030 & $1.14^{*}$ & $1.07-1.21$ \\
\hline Abs. maximum lateral plane moment arm $(\mathrm{cm})$ & $49.31(4.31)$ & $51.86(3.63)$ & 0.189 & 0.037 & $1.21^{*}$ & $1.12-1.30$ \\
\hline Abs. maximum sagittal plane moment arm $(\mathrm{cm})$ & $56.66(5.07)$ & $59.67(4.18)$ & 0.145 & 0.029 & $1.16^{*}$ & $1.09-1.22$ \\
\hline Abs. maximum sagittal trunk angle (degrees) & $48.42(11.92)$ & $51.98(9.71)$ & 0.015 & 0.012 & 1.02 & $0.99-1.04$ \\
\hline Abs. maximum lateral trunk angle (degrees) & $11.80(1.43)$ & $14.30(1.90)$ & 1.067 & 0.121 & $2.91^{*}$ & $2.29-3.68$ \\
\hline Maximum right lateral trunk angle (degrees) & $13.60(2.40)$ & $14.62(2.41)$ & 0.108 & 0.059 & 1.11 & $0.99-1.25$ \\
\hline Maximum left lateral trunk angle (degrees) & $11.80(1.43)$ & $14.30(1.89)$ & 1.067 & 0.121 & $2.91^{*}$ & $2.29-3.68$ \\
\hline Maximum sagittal trunk flexion velocity (degree/s) & 66.95 (11.43) & $80.71(13.44)$ & 0.078 & 0.011 & $1.08^{*}$ & $1.06-1.10$ \\
\hline Maximum sagittal trunk extension velocity (degree/s) & $82.70(14.11)$ & $86.45(15.78)$ & 0.023 & 0.009 & $1.02^{*}$ & $1.01-1.04$ \\
\hline Maximum sagittal trunk acceleration (degree $\left./ \mathrm{s}^{2}\right)$ & $660.18(114.79)$ & 760.66 (134.29) & 0.008 & 0.001 & 1.01 & $1.00-1.02$ \\
\hline Maximum sagittal trunk deceleration $\left(\right.$ degree/ $\left.\mathrm{s}^{2}\right)$ & $626.25(117.94)$ & $725.92(133.35)$ & 0.008 & 0.001 & 1.01 & $1.00-1.02$ \\
\hline Abs. maximum lateral trunk velocity (degree/s) & 97.50 (14.39) & $112.52(17.94)$ & 0.062 & 0.010 & $1.06^{*}$ & $1.04-1.08$ \\
\hline Maximum rightward lateral trunk velocity (degree/s) & 82.85 (12.29) & $96.89(16.06)$ & 0.066 & 0.010 & $1.07^{*}$ & $1.05-1.09$ \\
\hline Maximum leftward lateral trunk velocity (degree/s) & $82.95(13.63)$ & $96.67(16.11)$ & 0.070 & 0.011 & $1.07^{*}$ & $1.05-1.10$ \\
\hline Maximum lateral trunk acceleration (degree/s $\mathrm{s}^{2}$ ) & 785.29 (124.32) & 922.67 (154.08) & 0.007 & 0.001 & 1.01 & $1.00-1.01$ \\
\hline Maximum lateral trunk deceleration (degree $/ \mathrm{s}^{2}$ ) & $785.86(117.58)$ & $918.58(151.48)$ & 0.008 & 0.001 & 1.01 & $1.00-1.01$ \\
\hline Maximum box up acceleration $\left(\mathrm{m} / \mathrm{s}^{2}\right)$ & $8.46(3.15)$ & $12.92(5.08)$ & 0.285 & 0.038 & $1.33^{*}$ & $1.24-1.43$ \\
\hline Maximum box up deceleration $\left(\mathrm{m} / \mathrm{s}^{2}\right)$ & $4.79(1.51)$ & $6.92(2.24)$ & 0.551 & 0.075 & $1.74^{*}$ & $1.50-2.01$ \\
\hline \multicolumn{7}{|l|}{ Timing variables } \\
\hline Duration (s) & $2.38(0.69)$ & $3.09(0.71)$ & 2.082 & 0.262 & $8.02^{*}$ & $4.80-13.42$ \\
\hline Duration of nonload exposure (s) & $20.58(11.46)$ & $20.74(8.21)$ & 0.038 & 0.016 & $1.04^{*}$ & $1.01-1.07$ \\
\hline Duration of get $(\mathrm{s})$ & $0.60(0.16)$ & $0.69(0.12)$ & $* * *$ & $* * *$ & $* * *$ & $* * *$ \\
\hline Duration of carry (s) & $1.48(0.54)$ & $2.07(0.61)$ & 1.950 & 0.276 & $7.03^{*}$ & 4.09-12.09 \\
\hline Duration of place $(s)$ & $0.47(0.16)$ & $0.50(0.11)$ & $* * *$ & $* * *$ & $* * *$ & $* * *$ \\
\hline Percent time of maximum dynamic lift force & $50.45(6.93)$ & $54.57(4.73)$ & 0.185 & 0.028 & $1.20^{*}$ & $1.14-1.27$ \\
\hline Percent time of abs. maximum dynamic slide force & $48.17(5.68)$ & 49.09 (3.29) & 0.103 & 0.037 & $1.11^{*}$ & $1.03-1.19$ \\
\hline Percent time of abs. maximum dynamic lift/slide force & $50.11(7.00)$ & $54.04(4.24)$ & 0.201 & 0.030 & $1.22^{*}$ & $1.15-1.30$ \\
\hline $\begin{array}{l}\text { Percent time of abs. maximum static transverse plane } \\
\text { load moment }\end{array}$ & $46.07(7.99)$ & $50.31(5.85)$ & 0.072 & 0.023 & $1.07^{*}$ & $1.03-1.12$ \\
\hline $\begin{array}{l}\text { Percent time of abs. maximum static forward-bending } \\
\text { load moment }\end{array}$ & $46.08(8.02)$ & $50.73(5.64)$ & 0.085 & 0.024 & $1.09^{*}$ & $1.04-1.14$ \\
\hline
\end{tabular}


Table 4. Continued

\begin{tabular}{|c|c|c|c|c|c|c|}
\hline Variable (Units) & $\begin{array}{l}\text { Low Risk, } \\
\text { Mean (SD) }\end{array}$ & $\begin{array}{l}\text { High Risk, } \\
\text { Mean (SD) }\end{array}$ & Beta & $\begin{array}{l}\text { Standard } \\
\text { Error }\end{array}$ & $\begin{array}{l}\text { Odds } \\
\text { Ratio }\end{array}$ & $\begin{array}{l}95 \% \text { Confidence } \\
\text { Interval }\end{array}$ \\
\hline $\begin{array}{l}\text { Percent time of abs. maximum static side-bending load } \\
\text { moment }\end{array}$ & $52.39(3.34)$ & $50.11(3.17)$ & -0.241 & 0.044 & $0.79^{*}$ & $0.72-0.86$ \\
\hline Percent time of abs. dynamic forward-bending load moment & $47.05(8.10)$ & $53.49(5.48)$ & 0.158 & 0.023 & $1.17^{*}$ & $1.12-1.23$ \\
\hline $\begin{array}{l}\text { Percent time of abs. maximum side-bending dynamic load } \\
\text { moment }\end{array}$ & $52.14(4.99)$ & $53.32(3.66)$ & 0.120 & 0.034 & $1.13^{*}$ & $1.05-1.21$ \\
\hline $\begin{array}{l}\text { Percent time of abs. maximum dynamic transverse plane } \\
\text { load moment }\end{array}$ & $47.00(8.03)$ & $53.45(5.62)$ & 0.161 & 0.023 & $1.17^{*}$ & $1.12-1.23$ \\
\hline Percent time of absolute forward-bending resultant (sagittal) moment & $52.05(5.93)$ & $56.23(4.12)$ & 0.222 & 0.032 & $1.25^{*}$ & $1.17-1.33$ \\
\hline Percent time of abs. maximum dynamic resultant moment & $51.66(6.13)$ & $55.72(4.32)$ & 0.196 & 0.030 & $1.22^{*}$ & $1.15-1.29$ \\
\hline Percent time of abs. maximum dynamic twisting slide moment & $49.52(4.88)$ & $48.39(5.92)$ & -0.053 & 0.033 & 0.95 & $0.89-1.01$ \\
\hline $\begin{array}{l}\text { Percent time of abs. maximum dynamic forward-bending } \\
\text { slide moment }\end{array}$ & $46.53(11.41)$ & $48.23(5.82)$ & 0.054 & 0.019 & $1.06^{*}$ & $1.02-1.10$ \\
\hline $\begin{array}{l}\text { Percent time of abs. maximum dynamic lateral plane slide } \\
\text { moment }\end{array}$ & $45.89(11.28)$ & $47.29(0.96)$ & 0.049 & 0.012 & $1.05^{*}$ & $1.01-1.10$ \\
\hline $\begin{array}{l}\text { Frequency (lifts/min) } \\
\text { Individual variables }\end{array}$ & $2.81(1.34)$ & 1.91 & -1.080 & 0.160 & $0.34^{*}$ & $0.25-0.46$ \\
\hline Average body mass index $\left(\mathrm{kg} / \mathrm{m}^{2}\right)$ & $27.72(2.26)$ & $27.54(2.55)$ & -0.099 & 0.061 & 0.91 & $0.80-1.02$ \\
\hline Average age of those on the job (yrs) & $38.49(5.87)$ & $36.80(5.65)$ & 0.009 & 0.024 & 1.01 & $0.96-1.06$ \\
\hline Average weight of those on the job at baseline $(\mathrm{kg})$ & $86.17(8.68)$ & $86.35(9.38)$ & -0.037 & 0.016 & 0.96 & $0.93-1.00$ \\
\hline Average height of those on the job at baseline $(\mathrm{cm})$ & $176.09(4.62)$ & $176.88(5.53)$ & -0.050 & 0.026 & 0.95 & $0.90-1.00$ \\
\hline Percentage of males on the job at baseline & $0.83(0.26)$ & $0.84(0.25)$ & $* * *$ & $* * *$ & $* * *$ & $* * *$ \\
\hline Indicator of Hispanic or Latino ethnicity (see Table 2) & $0.07(0.12)$ & $0.05(0.10)$ & -0.782 & 1.201 & 0.46 & $0.04-4.82$ \\
\hline Indicator of smoking status (see Table 2) & $0.53(0.35)$ & $0.54(0.22)$ & -0.385 & 0.535 & 0.68 & $0.24-1.94$ \\
\hline Length of time worked at the company (see Table 2) & $3.26(0.70)$ & $2.77(1.03)$ & -0.248 & 0.136 & 0.78 & $0.60-1.02$ \\
\hline Length of time worked on current job (see Table 2) & $2.77(0.64)$ & $2.43(0.78)$ & -0.338 & 0.164 & $0.71^{*}$ & $0.52-0.98$ \\
\hline Length of time doing this kind of work (see Table 2) & $3.65(0.65)$ & $3.26(0.83)$ & -0.687 & 0.192 & $0.50^{*}$ & $0.34-0.73$ \\
\hline Hours per week worked (see Table 2) & $1.24(0.45)$ & $1.00(0.43)$ & -1.427 & 0.326 & $0.24^{*}$ & $0.13-0.46$ \\
\hline Baseline job control & $3.03(0.45)$ & $2.76(0.44)$ & -0.973 & 0.316 & $0.38^{*}$ & $0.20-0.70$ \\
\hline Baseline social support from supervisor & $1.73(0.47)$ & $1.79(0.35)$ & 0.643 & 0.338 & 1.90 & $0.98-3.69$ \\
\hline Baseline social support from co-workers & $1.87(0.47)$ & $1.82(0.28)$ & 0.613 & 0.431 & 1.85 & $0.79-4.30$ \\
\hline Baseline job satisfaction & $2.32(0.41)$ & $2.19(0.37)$ & -0.751 & 0.376 & $0.47^{*}$ & $0.23-0.98$ \\
\hline Baseline perception of physical demand rating & $5.60(1.64)$ & $5.76(1.43)$ & 0.189 & 0.097 & 1.21 & $1.00-1.46$ \\
\hline
\end{tabular}

* Significant odds ratio at $P<0.05$

***Odds ratio could not be calculated for these variables.

Abs. indicates absolute value.

\section{Multivariate Model of Exposure}

A multivariate model predicting decrease in spine function (impairment) was developed based on CART exploration of variables. The model is shown in Table 5. Three variables used in this model include maximum right lateral trunk velocity, timing of the maximum dynamic asymmetric load moment exposure, and the magnitude of the dynamic sagittal bending moment. It should be emphasized that (unlike the linear risk analysis shown in Table 4) this analysis considered the risk associated with combinations of variables that were above or below the given threshold values (indicated in Table 5 as "cutpoints"). Thus, Table 5 indicates that there exist specific key thresholds (cut points) for these values above which

Table 5. Multivariate Model Relating Physical Exposure and Reduction in Back Function

\begin{tabular}{lcccc}
\hline Variable & Cut Point & Beta & $\begin{array}{c}\text { Odds } \\
\text { Ratio }\end{array}$ & $\begin{array}{c}\text { Confidence } \\
\text { Interval }\end{array}$ \\
\hline $\begin{array}{l}\text { Lateral trunk velocity (Rt.) } \\
\begin{array}{c}\text { Timing (\%) of maximum } \\
\quad \text { dynamic asymmetric }\end{array}\end{array}$ & $>84.1$ degree/s & 3.559 & 35.14 & $14.1-87.7$ \\
$\begin{array}{l}\text { load moment } \\
\begin{array}{c}\text { Dynamic resultant sagittal } \\
\text { bending moment }\end{array}\end{array}$ & 3.252 & 25.84 & $8.5-78.2$ \\
\hline
\end{tabular}

risk increases significantly. This model resulted in excellent sensitivity $(85 \%)$ and specificity $(87.5 \%)$ as well as excellent positive predictive value $(89.5 \%)$ and negative predictive value $(82.4 \%)$.

Although this model is intended to be a cut point model, in-depth analyses also indicate that the model also performs well when considered as a linear model using continuous variables instead of simply observing when exposure measures are above or below the cut points. When considered linearly, the sensitivity is $70 \%$ and the specificity is $81 \%$. This indicates that the relationship of the variables to the functional impairment measure is relatively linear across the observed range of values.

\section{- Discussion}

This study has demonstrated, consistent with our first hypothesis, that through precise exposure quantification, it is possible to identify relationships between physical work exposure and decreases in spine kinematic function. Furthermore, previous studies ${ }^{13-15,21,22}$ have demonstrated that functional kinematic compromise is closely related to LBP. Therefore, it is reasonable to expect that the model described in this article is a reason- 
Figure 4. Three-dimensional comparison of high-risk jobs compared with low-risk jobs relative to the 3 variables contained in the multivariate model. The significance of the variable thresholds or cut points along with the interactive nature of the variables is evident.

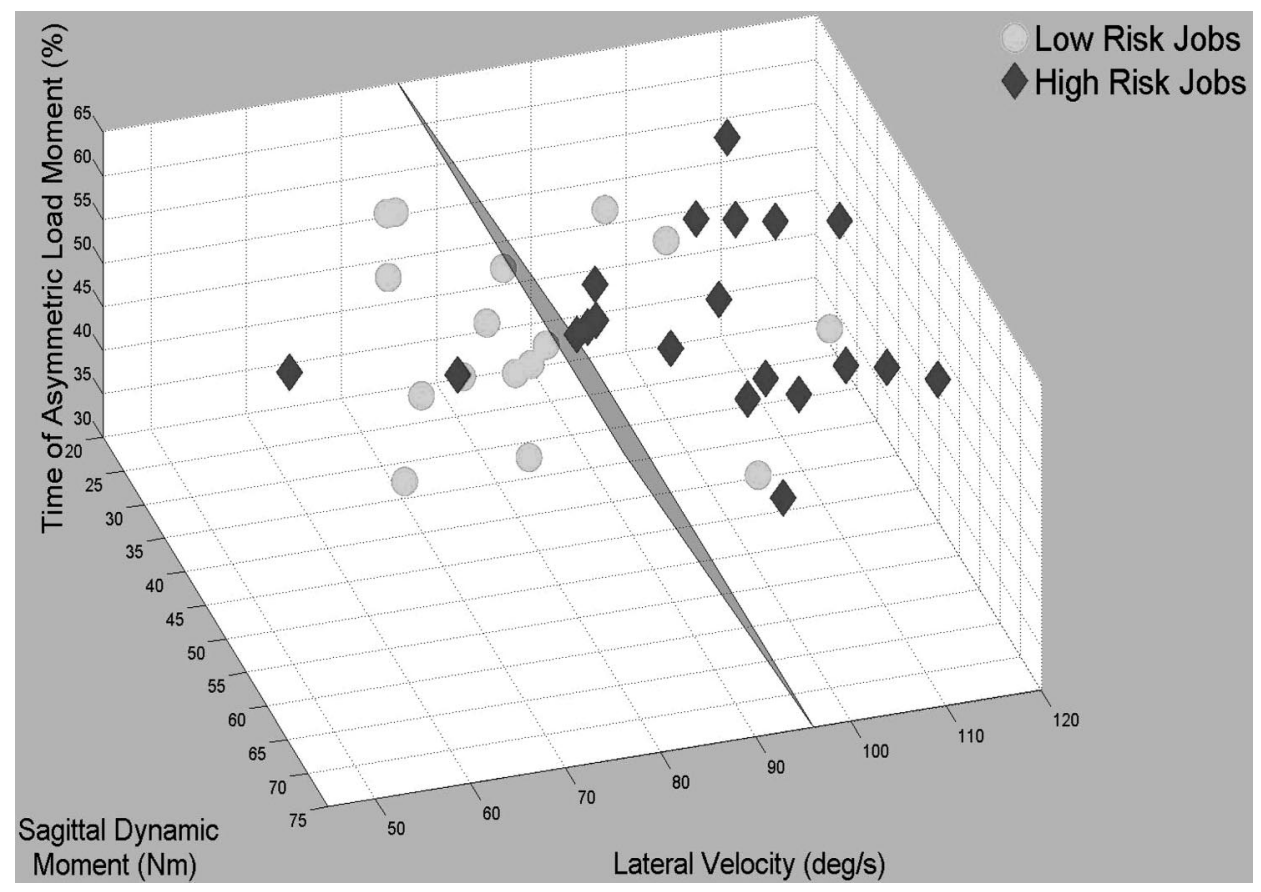

able predictor of changes in level of LBP development, given exposures in distribution center environments.

There are several observations worthy of emphasis in this analysis. First, all the variables that entered the model were dynamic (time-linked) variables. This study has been able, for the first time, to investigate dynamic load motion (and the effect on load magnitude) as well as dynamic back motion continuously in the workplace. Thus, dynamic assessment of physical exposure seems to add a level of information not provided by traditional static measures or through more easily accessed gross descriptions of work exposure. This study emphasizes that precise quantification of physical exposure is an important factor in predicting risk of low back functional changes.

Second, the dynamic load moment that predicted risk in our multivariate model represents both lifting moment and push or pull moment in the sagittal plane. Previous biomechanical assessments have studied load moment due to the gravitation (up and down) component of force exclusively. It should also be understood that, in this study, load moment refers to the external moment imposed by the manipulation of the object lifted. This analysis does not consider the moment exposure due to both the trunk mass and position. It only considers the increase in risk resulting from the external object being handled. However, because external objects tend to impose greater moments about the spine, this variable is considered important in understanding risk.

Our findings suggest that the loading of the spine is more complex in that a multidimensional vector of load is better associated with risk. From a biomechanical standpoint, a multidimensional vector of force would result in greater trunk muscle co-contraction and more complex loading on the spine tissues. This situation, once again, emphasizes the importance of precise quantification of exposure.

Third, to our knowledge this is the first study to explore the timing of physical exposure events and the relationship with spine function impairment. We were able to identify a significant linear association between risk and our temporal measures of interest. Specifically, the duration of the lift and the duration of carry seem to be linearly related to risk throughout the range of observations. These findings suggest that biomechanical studies of load carrying are warranted. In addition, collectively, these variables reinforce the concept of cumulative loading as a risk factor for LBP. The multivariate model also contained a timing variable associated with the occurrence of the peak asymmetric load moment. Risk increased if the moment peaked later in the lift (greater than $47.6 \%$ through the lift). Normally, peak load occurs early in the lift. Thus, this finding suggests that in high-risk jobs the load was being extended away from the body at the destination, thereby indicating an eccentric loading of the paraspinal muscles. ${ }^{23}$

Finally, there is a true interaction occurring between the multivariate model variables. Examination of the variable correlation matrix also indicates that these model variables are also representative of numerous other biomechanical measures by way of their correlations. Figure 4 indicates how the low-risk jobs compare with the high-risk jobs relative to the 3 variables contained in the multivariate model. This comparison can also be made by viewing the supplemental video file (Supplemental Digital Content 1, video, available at: http://links.lww.com/BRS/A410). When observing this state space from different angles, it is apparent that the high- and low-risk jobs are confined to specific quadrants of the state space along the various dimensions. This 
indicates that when the variables are considered collectively, the cut points represent multivariate thresholds of risk above which risk increases significantly. This is also apparent from the comparison of the continuous multivariate model with the cut point multivariate model. Although the continuous model represents improvement in risk prediction with every unit change in the variables, the cut point model performs significantly better in predicting risk and indicates (as does Figure 4) that risk increases markedly above certain threshold values. Thus, these cut point values represent "how much exposure is too much exposure" in a multivariate sense and, as hypothesized, permit us to identify high risk and low risk occupational environments. Furthermore, because this study has investigated the full range of exposures, these cut points can now be used as thresholds for more conventional epidemiologic studies.

Some of the variables examined in this investigation are comparable with our previous investigations of dynamic spine motion and risk. ${ }^{5}$ Although spine motion was measured differently in this study compared with this previous investigation, we have been able to translate the position and velocity measures between these 2 measurement systems. In general, this study confirms the levels of spine motion associated with risk in this previous study. ${ }^{18}$ Thus, this study reinforces our previous findings.

Several study limitations should also be recognized. First, these findings are unique to distribution center environments. These environments are extremely fast paced with high frequency of lift throughout the workday. Thus, these findings apply to similar types of highfrequency lifting environments. However, given the shift in many modern economies from less manufacturing to more distribution, these results should be applicable to many environments. Second, a health-effects follow-up period of at least 6 months might be considered relatively short by some investigators. Our initial enrollment of workers in this study was excellent with $<10$ workers declining to participate in the study. However, distribution center environments are notorious for turnover. Many of these facilities reported $300 \%$ annual turnover. This was confirmed by our $50 \%$ follow-up rate. Hence, although a longer follow-up period would have been desirable, it would have been impractical. It may be that the "survivors" in this analysis over represent healthy workers. However, many of the survivors demonstrated decrements in spine function. Besides, we found very significant effects with our follow-up period, which may indicate the severity of the environments we studied. Third, the measure of spine function in this study is a derivative of LBP. However, our previous studies have shown that the kinematic function measure is closely related to LBP. In addition, forthcoming studies will show how similar models relate to reported LBP. Fourth, it should be emphasized that this study examined workers who were currently active in distribution centers. Thus, these risk-exposure thresholds would be applica- ble to active workers and may not be applicable to patients returning to work after a low back problem. Finally, our study used instrumented handles that were used to lift the loads in the distribution centers. These handles were necessary to quantify load exposure. However, they may have altered the way in which the workers performed their tasks. Previous studies that have examined the influence of handle inclusion during lifting have reported that inclusion of handles has the effect of making the box appear about $4.5 \mathrm{~kg}$ lighter in terms of spine loading. ${ }^{24,25}$ Thus, we expect that under non-handle lifting conditions, the risk might even be greater than stated here. Nonetheless, we believe that the benefits gained from quantification of the physical exposure far outweigh the alteration of lifting behavior that might have occurred.

\section{- Key Points}

- Precise quantitative measures of dynamic physical work exposure are related to decreases in spine function indicative of back pain.

- Both univariate and multivariate associations with impaired function have been identified.

- Thresholds of exposure above which risk increases significantly have been identified.

- Three key exposure variables (maximum right lateral trunk velocity, time of the maximum dynamic asymmetric load moment exposure, and the magnitude of the dynamic sagittal bending moment), when considered collectively, predict impairment well (sensitivity of $85 \%$ and a specificity of $87.5 \%$ ).

- These findings have helped us understand how and at what levels physical exposure to work can contribute to the multidimensional causes of low back pain in distribution environments.

Supplemental digital content is available for this article. Direct URL citations appear in the printed text, and links to the digital files are provided in the HTML text of this article on the journal's Web site (www.spinejournal. com).

\section{References}

1. NRC. Musculoskeletal Disorders and the Workplace: Low Back and Upper Extremity. Washington, DC: National Academy of Sciences, National Research Council, National Academy Press; 2001:492.

2. Steiner C. Man vs. machine. Forbes 2007;180:104-9.

3. Lotters F, Burdorf A, Kuiper J, et al. Model for the work-relatedness of low-back pain. Scand J Work Environ Health 2003;29:431-40.

4. Marras WS, Lavender SA, Leurgans SE, et al. Biomechanical risk factors for occupationally related low back disorders. Ergonomics 1995;38:377-410.

5. Marras WS, Lavender SA, Leurgans SE, et al. The role of dynamic threedimensional trunk motion in occupationally-related low back disorders. The effects of workplace factors, trunk position, and trunk motion characteristics on risk of injury. Spine 1993;18:617-28.

6. Norman R, Wells R, Neumann P, et al. A comparison of peak vs cumulative physical work exposure risk factors for the reporting of low back pain in the automotive industry. Clin Biomech (Bristol, Avon) 1998;13:561-73. 
7. Punnett L, Fine LJ, Keyserling WM, et al. Back disorders and nonneutral trunk postures of automobile assembly workers. Scand J Work Environ Health 1991;17:337-46.

8. Waters TR, Baron SL, Piacitelli LA, et al. Evaluation of the revised NIOSH lifting equation. A cross-sectional epidemiologic study. Spine 1999;24:38694; discussion 395.

9. Bernard BP, ed. Musculoskeletal Disorders and Workplace Factors: A Critical Review of Epidemiologic Evidence for Work-Related Musculoskeletal Disorders of the Neck, Upper Extremity, and Low Back. Cincinnati, OH: Department of Health and Human Services (DHHS), Public Health Service, Centers fir Disease Control, National Institute for Occupational Safety and Health (NIOSH); 1997.

10. Marras WS, Allread WG, Burr DL, et al. Prospective validation of a lowback disorder risk model and assessment of ergonomic interventions associated with manual materials handling tasks. Ergonomics 2000;43:1866-86.

11. Marras WS, Lavender SA, Ferguson SA, et al. Instrumentation for measuring dynamic spinal load moment exposures in the workplace. J Electromyogr Kinesiol 2009;20:1-9.

12. Baron S, Hales T, Hurrell J. Evaluation of symptom surveys for occupational musculoskeletal disorders. Am J Ind Med 1996;29:609-17.

13. Ferguson SA, Marras WS. Revised protocol for the kinematic assessment of impairment. Spine J 2004;4:163-9.

14. Marras WS, Ferguson SA, Gupta P, et al. The quantification of low back disorder using motion measures. Methodology and validation. Spine 1999; 24:2091-100.

15. Marras WS, Parnianpour M, Ferguson SA, et al. The classification of ana- tomic- and symptom-based low back disorders using motion measure models. Spine 1995;20:2531-46.

16. Marras WS, Lewis KE, Ferguson SA, et al. Impairment magnification during dynamic trunk motions. Spine 2000;25:587-95.

17. Ferguson SA, Marras WS, Burr D, et al. Quantification of a meaningful change in low back functional impairment. Spine 2009;34:2060-5.

18. Marras WS, Lavender SA, Ferguson SA, et al. Quantitative biomechanical workplace exposure measures: distribution centers. Journal of Electromyography and Kinesiology. Appl Ergon In press.

19. Steinberg D, Colla P. CART-Classification and Regression Trees. San Diego, CA: Salford Systems; 1997.

20. Breiman L, Friedman J, Olshen R, et al. Classification and Regression Trees. Pacific Grove, CA: Wadsworth; 1984.

21. Ferguson SA, Marras WS, Gupta P. Longitudinal quantitative measures of the natural course of low back pain recovery. Spine 2000;25:1950-6.

22. Marras WS, Wongsam PE. Flexibility and velocity of the normal and impaired lumbar spine. Arch Phys Med Rehabil 1986;67:213-7.

23. de Looze MP, Toussaint HM, van Dieen JH, et al. Joint moments and muscle activity in the lower extremities and lower back in lifting and lowering tasks. J Biomech 1993;26:1067-76.

24. Marras WS, Davis KG, Kirking BC, et al. A comprehensive analysis of lowback disorder risk and spinal loading during the transferring and repositioning of patients using different techniques. Ergonomics 1999;42:904-26.

25. Marras WS, Granata KP, Davis KG, et al. Effects of box features on spine loading during warehouse order selecting. Ergonomics 1999;42:980-96. 